\title{
IS HABITAT FRAGMENTATION A FACTOR IN THE DECLINE OF THE BURROWING OWL IN SASKATCHEWAN?
}

ROBERT WARNOCK, Department of Biology, University of Regina, Regina, SK. S4S OA2. Current Addresses: Department of Biology, University of Saskatchewan, 112 Science Place, Saskatoon SK. S7N 5E2 and Canadian Wildlife Service, 115 Perimeter Road, Saskatoon, SK. S7N 0X4. E-mail: Warnock@duke.usask.ca

\section{Introduction}

Worldwide, habitat destruction is considered one of the leading causes of wildlife extinctions. However, wildlife populations may decline not only when habitat is directly eliminated, but also when habitat is degraded to varying degrees. Habitat fragmentation is the transformation of large continuous blocks of habitat into much smaller, isolated patches. This process has been recognized as one of the most important issues in modern conservation biology because the impact on wildlife populations is greater than what is simply predicted on the basis of the area of the habitat removed. ${ }^{17}$

The Great Plains of North America is one of the most heavily modified and fragmented ecosystems in the world mostly due to agriculture. ${ }^{16}$ These grasslands have variable or high plant species diversity because of differences in climatic conditions, and the frequency and intensity of disturbances such as fire. Modern agricultural practices, the elimination of most grasslands, removal of native grazers, fire suppression, the expansion of woody vegetation and recent increases in some predators and cowbirds are often cited as possible causes of declines. ${ }^{5,7,14,19}$ Reproductive potential, dispersal ability, food supply, habitat selection, rarity and vulnerability to human actions of species interact with the size, shape and arrangement of habitat fragments, surrounding matrix and habitat changes over time. These interactions determine the likelihood of survival of small isolated populations and ultimately, the species composition of communities. Habitat related issues are thought to be primary causes of declines of Short-eared Owls, Piping Plovers, Long-billed Curlews, Ferruginous Hawks, Swift Foxes, Baird's Sparrows and Loggerhead Shrikes on the Canadian Prairies. $^{10}$

The Burrowing Owl (Athene cunicularia) is a prairie species that has been in precipitous decline in Canada over the last decade (from 2500 pairs to about 1000 pairs). ${ }^{8}$ As a result, the Committee on the Status of Endangered Wildlife in Canada (COSEWIC) has classified the Burrowing Owl as an endangered species. $^{21}$ It has been estimated that the present extent of Burrowing Owl breeding habitat is only 27 percent of the present total of cultivated and pastureland in Saskatchewan. ${ }^{21}$ it should be noted that this estimate includes land that is not suitable for Burrowing Owls. As a result, conversion of Burrowing Owl häbitat has 
occurred more quickly (up to 3 percent per year from 1979 to 1986) than the rate of reduction in pastureland suggests ( 0.8 percent per year between 1966 and 1991). ${ }^{9,21}$

Methods. The Burrowing Owl was used to illustrate the situation on the Canadian prairies and as a "focal species" for prairie conservation. The relationship between landscape fragmentation patterns and the spatial and temporal distribution and population turnover of Saskatchewan Burrowing Owls was investigated on 125,664 ha circular plots. $^{20}$ Data were collected from 152 Operation Burrowing Owl (OBO) plots and 250 random plots located on 1990 LANDSAT-TM satellite images and 1:250,000 scale topographic maps. The number of Burrowing Owl pairs were recorded in each OBO plot. Habitat continuity, patch dimensions and isolation of sites were measured and analyzed with univariate and multivariate statistical methods. ${ }^{20}$

\section{Results and Discussion}

Spatial Distribution. The spatial arrangement of grassland patches was significantly different between the core and peripheral areas of the Burrowing Owl range. ${ }^{20}$ The core (Moose Jaw-Regina south to U.S. Border) had at least $1.5 \mathrm{OBO}$ sites per $1000 \mathrm{~km}^{2}$ and the periphery (rest of the Saskatchewan Burrowing Owl range) had less than $1.5 \mathrm{OBO}$ sites per $1000 \mathrm{~km}^{2}$. Core owl sites had smaller patch dimensions and lower habitat continuity, but had greater owl site persistence probably due to immigration from a larger number of nearby owl sites than did peripheral owl sites.

Burrowing Owls did not nest randomly across the landscape in Saskatchewan. ${ }^{20}$ It appeared that owls preferred more fragmented but less isolated habitat in the core area. This preference may be due to factors such as burrow and prey availability. Abundance of Burrowing Owls is probably the greatest with lacustrine (old lake beds) soils, because of higher burrow availability. ${ }^{21}$ The lacustrine soil type was more limited (22.7 percent of landscape) in the core than in the periphery (33.3 percent of landscape) and this may have influenced the selection of more fragmented habitat in the core range. ${ }^{20}$ The quality of habitat patches in terms of vegetation structure, presence of fire and introduced plant species may also affect the distribution and population size of grassland birds, mammals and plants. ${ }^{5,6}$

Burrowing Owls do nest in small habitat patches and forage over other cover types. ${ }^{3,5}$ This is in contrast to grassland species that increase in numbers with patch size due to reduced nest predation and fewer cowbirds. ${ }^{5}$ In fragmented landscapes, Burrowing Owls may forage greater distances within larger home ranges and spend more time away from the nest, making them more vulnerable to predators; and therefore, less efficient at reproduction. ${ }^{3}$

Some of the highly fragmented sites used by Burrowing Owls had large numbers of pairs (15 or more) from 1987 to $1993 .^{20}$ Higher raptor densities in small habitat fragments has been reported previously by James. $^{11}$ Crowding into small patches can increase intraspecific competition that is manifested as foraging interference, aggression and cannibalism. Intraspecific competition is thought to be a major cause of nest abandonment and low productivity of dense Burrowing Owl colonies. $^{2}$ High densities of nests may attract predators while lower 
densities would force predators to concentrate on other prey. ${ }^{10}$ Chance events such as flooding and predation are also likely to increase the probability of nest site abandonment by Burrowing Owls. These events may explain the population decline of the Burrowing Owl in Saskatchewan. ${ }^{20}$

In highly fragmented areas, such as the core of the range, edge becomes important. Several studies have shown that artificial nests and natural nests can suffer greater predation rates when placed near edges. ${ }^{1,13}$ Owls nesting near edges would suffer greater predation from predators such as foxes that search more thoroughly along pasture edges near cover. ${ }^{21}$ For example, nest predation by badgers is a major cause of nest failure and abandonment in Burrowing Owls in Oregon. ${ }^{2}$ The Burrowing Owl may be more adversely affected by edge effects because of nesting in underground burrows and selection of pasture edges with good visibility at the start of the breeding season. ${ }^{21}$

Isolation might be less important in the core because the fragments although smaller were closer together and owl site density was greater than in the periphery. ${ }^{20}$ Nesting near other owls in the periphery may be important for successful dispersal and pairing success. In addition, isolation increases exposure to predators, increases delays in finding another owl colony, nest burrow, or mate, and lowers the feeding efficiency and thus decreases the probability of dispersal between owl sites.

Persistence. Continuity of habitat can be important to the persistence (or the presence) of grassland wildlife such as Burrowing Owls, clonal plants and small mammals over time. ${ }^{20}$ The positive correlation between persistence and habitat continuity is often attributed to larger subpopulations, reduced predation and fewer cowbirds, increased pairing and nesting success, lower rates of interspecific competition due to less crowding and increased probability of successful dispersal of individuals in the landscape. ${ }^{20}$

The negative correlation between Burrowing Owl persistence and amount of patch edge suggested edge effects in the peripheral area. ${ }^{20}$ Other studies have shown that increased nest predation can be greater on smaller patches and with increased proximity to patch edges. ${ }^{1,13}$ Persistence may have increased because of successful dispersal and higher reproductive success due to reduced edge effects such as nest predation and intraspecific competition.

James found direct patch size effects on the site persistence of Burrowing Owls but I found only indirect patch size effects. ${ }^{11,20}$ The number of breeding pairs did increase over time with patch size but small patches in the core. ${ }^{20}$ Patch size did indirectly affect owl site persistence by determining the number of owl pairs over time. Patch size may be most important when the landscape is heavily fragmented and there are no large patches, as in James' study. ${ }^{11}$ Larger patch sizes can increase the persistence of grassland species by reducing the probability of predation of individual birds and increasing pairing success.

Isolation also appeared to be important to Burrowing Owl persistence. Persistent owl sites appeared to have greater patch isolation in the core range. ${ }^{20}$ Lower patch isolation appeared to enhance Burrowing $\mathrm{Owl}$ 
year to year dispersal between patches in the core and decrease the probability of repeated use of isolated patches perhaps due to reduced dispersal risks. This pattern was also evident in data on the extirpation and occupancy of core owl sites. $^{20}$ In contrast, lower isolation and more numerous nearby owl sites appeared to increase the probability that the peripheral owl sites would be occupied the following year. ${ }^{20} \mathrm{Habi}$ tat modification at distant sites could decrease the persistence of existing Burrowing Owl sites by increasing the distance between sites and thus decreasing the probability of successful dispersal between owl sites. $^{21}$

\section{Population Turnover. Turnover} means a change in the composition of biological communities in a defined area due to either the local extinction or immigration of a species or both. ${ }^{20}$ MacArthur and Wilson's classic theory of island biogeography described extirpation and immigration as processes in a dynamic equilibrium. ${ }^{15}$ To my knowledge, my study is the first attempt to examine population turnover in a fragmented prairie landscape. ${ }^{20}$ Some possible important factors in the annual turnover of species include vegetation structure, site fidelity, surrounding land use, habitat connectedness and size and isolation of habitat fragments. $^{20}$

Persistent and occupied Burrowing Owl sites had higher levels of isolation in the core. In the core range, the negative impact of the isolation of patches may have been low for Burrowing Owls as compared to other organisms in different landscapes. When the isolation effects were relatively large, they influenced the spatial distribution of core and peripheral owl sites and the persistence of peripheral owl sites. ${ }^{20}$ Lower patch isolation appeared to enhance Burrowing Owl year-to-year dispersal between patches because of small dispersal risks in the core.

The amount of patch edge and several measures of habitat continuity were important to the difference between extirpated and persistent owl sites in the peripheral range. Edge effects may be important to the extirpation of owls from peripheral sites because of the negative correlation between peripheral owl site persistence and the amount of patch edge. ${ }^{20}$ Increased edge effects can contribute to lower reproductive success of birds. Burrowing Owls are known to move to different pastures, especially if there is nest failure due to predation. ${ }^{2}$ Habitat continuity was also important to the discrimination of extirpated and persistent owl sites in the peripheral range. ${ }^{20}$ Due to larger subpopulations, the local extinction of birds from habitat patches is less probable with increasing area and habitat continuity. ${ }^{20}$

The colonization of core Burrowing Owl sites appeared to be enhanced by increased habitat continuity. ${ }^{20}$ Colonization of core owl sites occurred on small fragments with minimal isolation and high surrounding continuity of habitat possibly because of reduced dispersal risks and sufficient resources. Isolation measures contributed significantly to the difference between colonized and uncolonized owl sites in the core and peripheral ranges.

As discussed earlier, occupancy of core owl sites was enhanced by increased isolation. Owls appeared less likely to move if there was no nearby patch or owl site, as has been observed for small mammals. ${ }^{21}$ Greater dispersal risks, s'ıch as 
predation, likely determine the probability of dispersal between habitat patches. Patch dimensions and habitat continuity were important to the differentiation between occupied and unoccupied Burrowing Owl sites. ${ }^{20}$ Occupancy of habitat patches by birds, mammals and arthropods is often positively correlated with patch area and habitat continuity. ${ }^{20}$ In the peripheral range, the amount of patch edge may be important to the occupancy as well as the extirpation of owl sites.

From 1987 to 1993, extirpation of examined $\mathrm{OBO}$ sites increased from 16 percent to 54 percent and occupancy of examined OBO sites decreased from 79 percent to 31 percent. ${ }^{20}$ These results support previous work documenting the decline of the Burrowing Owl population in Saskatchewan. ${ }^{8,} 12,21$ It is arguable that the patterns of habitat fragmentation contribute significantly to the decline of Burrowing Owl in Saskatchewan based on the correlations with Burrowing Owl spatial distribution, persistence and population turnover.

\section{Conservation Implications}

Burrowing Owls have the capacity for rapid population recovery because of their high reproductive potential and their broad prey spectrum. ${ }^{4}$ It is recommended that management focus on the core portion of the Burrowing Owl range in Saskatchewan because the core contains the majority of remaining owls and the population decline there appears to be less severe. ${ }^{20}$ Stabilizing the core will be critical for the long-term conservation of the Burrowing Owl in Saskatchewan. The core could then serve as a "source" where reproductive output is greater than mortality. The results of previous work suggest that maximizing the continuity of habitat and increasing the number of accessible patches with optimal dimensions would be a good strategy.

If the core Burrowing Owl population is stabilized, the focus could then shift to persistent peripheral owl sites. Occupancy could be enhanced in several ways. Removing marginal farmland from production could enlarge habitat patches and reduce isolation between nearby owl sites. In addition quality of habitat patches can be improved by a mix of short and taller vegetation and more burrows and patches within Burrowing Owl home ranges. These actions would also likely benefit other prairie wildlife species.

The conservation of the Burrowing Owl has a high level of support in Saskatchewan and a large number of habitat patches are already protected under Operation Burrowing Owl. ${ }^{21}$ Therefore, the Burrowing Owl could be used as an "focal species" for prairie conservation. OBO could also serve as a model for new land stewardship programs. OBO in Alberta evolved into Operation Grassland Community to include other threatened grassland species in the program and to develop a more ecosystem-based approach to conservation (Dave Scobie, pers. comm.). In addition, more habitat patches in private and public ownership could be protected. For example, the majority of known Burrowing Owl sites are on private land. The provincial and federal governments hold title to most of the remaining large blocks of prairie in Saskatchewan. However, the distribution of Burrowing Owls on these lands is poorly known. ${ }^{21}$ To increase the continuity of grassland habitat for Burrowing Owls and other species, additional private and publicly owned prairie habitat needs to be identified 
and protected through close coordination and cooperation between conservation agencies and private landowners and Crown land leasees. Carrying out the set of recommendations for the redesign of Canadian farm support programs, tax assesssments and Crown land policies by Thornton et al. would likely make it more economically advantageous for farmers to remove marginal land from cultivation and protect and rehabilitate wildlife habitat on their land. $^{18}$

In conclusion, it appears that patterns of habitat fragmentation do affect grassland wildlife. The Burrowing Owl is a good example because the abundance, persistence and distribution of Burrowing Owl sites were correlated with the patterns of habitat fragmentation. ${ }^{20}$ The conservation of the Burrowing Owl and the prairie ecosystem are linked. We can reduce the impacts of habitat fragmentation on Burrowing Owls and other grassland species and reduce costs of their recovery by protecting existing and creating additional grassland habitat.

Acknowledgments I wish to thank my supervisors, Paul James and Diane Secoy, and committee members, Mark Brigham and Joe Schmutz for their support of my M.Sc. research on the Burrowing Owl. I also wish to thank the following for providing support (data, equipment, logistics) to the Burrowing Owl project: Jim Duncan (Manitoba Conservation Data Centre), Zhonge "June" Guo (University of Regina), Heather Dundas (Nature Saskatchewan), John Polson (Saskatchewan Research Council), David Gauthier and Lorena Patino (Department of Geography, University of Regina), University of Regina Biology Department, Canadian Wildlife
Service, Saskatchewan Wildlife Branch, Saskatchewan Conservation Data Centre and the Canadian Burrowing Owl Recovery Team. I also thank Paul James, Keith Hobson and Stuart Houston for reviewing earlier drafts of this paper.

Research funding for the Burrowing Owl project was provided through a Saskatchewan Heritage Foundation Grant (No. 92-17R), two Nature Saskatchewan Scholarships, a Dennis Pattinson Memorial Scholarship (Saskatchewan Wildlife Federation), a Stephen R. Tully Memorial Grant (Raptor Research Foundation), a Government of Saskatchewan Partnerships '93 Grant, the Department of Biology and a Graduate Scholarship from the University of Regina. Additional funding for the Burrowing Owl project was provided by the World Wildlife Fund Canada, Environment Canada, Government of Saskatchewan, Nature Saskatchewan and Wildlife Habitat Canada.

1. BURGER, L.D., L.W. BURGER, Jr. and J. FAABORG. 1994. Effects of prairie fragmentation on predation on artificial nests. J. Wildl. Manage. 58: 249-254.

2. GREEN, G.A. and R.G. ANTHONY 1989. Nesting success and habitat relationships of Burrowing Owls in the Columbia Basin. Condor 91: 347-351.

3. HAUG, E.A. 1985. Observations on the Breeding Ecology of Burrowing Owls in Saskatchewan. Unpublished M.Sc. Thesis. University of Saskatchewan, Saskatoon.

4. HAUG, E.A., B.A. MILLSAP and M.S. MARTELL. 1993. Burrowing Owl (Athene cunicularia). In: A. Poole and F. Gill (eds.), The Birds of North America. No. 61. The Academy of Sciences, Philadelphia; The American Ornithologists Union, Washington, D.C.

5. HERKERT, J.R. 1994a. The effects of habitat fragmentation on midwestern grassland bird communities. Ecol. Appl. 4: 461-474. 
6. HERKERT, J.R. 1994b. Breeding bird communities of midwestern prairie fragments: The effects of prescribed burning and habitat-area. Nat. Areas J. 14: 128-135.

7. HERKERT, J.R. 1995. Analysis of midwestern breeding bird population trends: 1966-1993. Am. Midl. Nat. 134: 41-50.

8. HJERTAAS, D., S. BRETCHEL. K. De SMET, O. DYER, E.A. HAUG, G. HOLROYD, $P$. JAMES and J. SCHMUTZ. 1995. National Recovery Plan for the Burrowing Owl. Report No. 13. Recovery of Nationally Endangered Wildlife Committee, Ottawa.

9. HJERTAAS, D., and W. LYON. 1987. A stratified random survey for Burrowing Owls. Saskatchewan Wildlife Branch Technical Report 87-2. Saskatchewan Parks and Renewable Resources, Regina.

10. HOLROYD, G.L. 1996. Endangered species conservation. In: W.D. Willms and J.F Dormaar (eds.), Proceedings of the Fourth Prairie Conservation and Endangered Species Workshop, February 1995 at The University of Lethbridge and Lethbridge Community College, Lethbridge, Alberta. Natural History Occasional Paper No. 23. Provincial Museum of Alberta, Edmonton. pp. 227-232.

11. JAMES, P.C. 1993. Habitat fragmentation and Burrowing Owls in Saskatchewan. In: G.L. Holroyd, H.L. Dickson, M. Regnier and H.C. Smith (eds.), Proceedings of the Third Prairie Conservation and Endangered Species Workshop, February 1992 at Brandon University, Brandon, Manitoba. Natural History Occasional Paper No. 19. Provincial Museum of Alberta, Edmonton. pp. 193-194.

12. JAMES, P.C., T.J. ETHIER and M.K. TOUTLOFF. 1996. Parameters of a declining Burrowing Owl population in Saskatchewan. Raptor Research Rep. In Press.

13. JOHNSON, R.G., and S.A. TEMPLE. 1990. Nest predation and brood parasitism of tallgrass prairie birds. J. Wildl. Manage. 54: 106-111.

14. KNOPF, F.L. 1994. Avian assemblages on altered grasslands. Studies in Avian Biol. 15: 247-257.

15. MACARTHUR, R.H. and E.O. WILSON. 1967. The Theory of Island Biogeography. Princeton University Press. Princeton, New Jersey.

16. ROWE, J.S. 1987. One hundred years of land use. Blue Jay 45: 127 139.

17. TERBORGH, J. 1989. Where Have All the Birds Gone? Princeton University Press, Princeton, New Jersey.

18. THORNTON, F., J. BOWMAN and D. STRUTHERS. 1993, 1994, 1995. Agricultural policy review: Parts 1, 2, 3 and 4. Blue Jay 51: 5-9, 51:65-71, 52:185-189, 53:1-14.

19. WARNER, R.E. 1994. Agricultural land use and grassland habitat in IIInois: Future shock for midwestern birds? Cons. Biol. 8: 147-156.

20. WARNOCK, R.G. 1996. Spatial, Temporal and Turnover Dynamics of Burrowing Owl (Athene cunicularia) Distribution in the Extensively Fragmented Grasslands of Saskatchewan. Unpublished M.Sc. Thesis. University of Regina, Regina.

21. WELLICOME, T.I. and E.A. HAUG. 1995. Updated Report on the Status of the Burrowing Owl (Athene cunicularia) in Canada. Committee on the Status of Endangered Wildlife in Canada, Ottawa. 